\title{
Utilisation of an intervention to support students on the autism spectrum: Examining teachers' responses to Finished! The On-task Toolkit
}

Students on the autism spectrum can face significant challenges in accessing formal education. Autism spectrum disorder (ASD) is a life-long neurological disorder characterised by differences in social communication, as well as restrictive, repetitive patterns of behaviour, which may include an insistence on sameness, inflexibility, and/or differences in responses to sensory stimuli (American Psychiatric Association, 2013). For individuals on the spectrum, general education classrooms, with their complex social interactions, multiple transitions and task demands, and varied sensory stimuli, can be a source of stress (Humphrey \& Lewis, 2008). There is a recognised need for strategies to support students on the spectrum. In Australia, rates of students diagnosed as being on the autism spectrum have been increasing, with more than three quarters of the 164,000 individuals with an ASD diagnosis in 2015 under 24 years of age (Australian Bureau of Statistics, 2016). Four out of five students on the spectrum are reported to have difficulty at school (Australian Bureau of Statistics, 2016), and the majority of these students attend general education classes (Autism Awareness, 2014). Teachers in these settings are not necessarily knowledgeable about autism and may not be confident in their ability to provide adequate support to students on the spectrum (Soto-Chodiman, Pooley, Cohen, \& Taylor, 2012).

A number of practices designed to support students on the spectrum have been identified as having sufficient, high-quality research demonstrating their efficacy to be considered evidence-based (National Autism Center, 2015; Wong et al., 2015). The National Standards Project (National Autism Center, 2015) identified 14 evidence-based practices, and Wong et al. (2015) identified 27. These practices include the use of modelling, prompting, and schedules, as 
well as comprehensive treatment approaches such as cognitive behavioural intervention and functional behaviour assessments. While the use of some of these practices is well established, there is a widely acknowledged lag in the translation of evidence-based practices to general educational settings (Cook \& Odom, 2013; Dingfelder \& Mandell, 2011; Kasari \& Smith, 2013), with some estimating the delay in the implementation of educational interventions to be 20 years or more (Dingfelder \& Mandell, 2011; Walker, 2004). For general education teachers, whose time and resources may be scarce, there may be limited opportunities to seek out research findings. In addition, knowledge of evidence-based practices alone may be insufficient to ensure implementation, with many potential barriers to using practices that have been devised and tested in controlled or clinical environments (Dearing, 2009; Kasari \& Smith, 2013). There is, then, a need for researchers to engage with teachers to find effective ways of exchanging information and to maximise the social and ecological validity of evidence-based practices (Dykstra Steinbrenner et al., 2015; Parsons et al., 2013).

The present study was the utilisation phase of a project exploring the use of two structured teaching strategies - visual schedules and work systems - as whole class practices to support students on the autism spectrum to stay on task in general education settings. Following on from an earlier evaluation phase which documented the successful implementation of these strategies (citation withheld for current blind review), the current study examined teachers' responses to an information package which described the strategies by collecting feedback through an online survey and follow-up interviews. The overall objective of the current study was to facilitate the translation of strategies already supported by research into sustainable classroom practice. This objective was addressed by examining teachers' views regarding the usefulness of the strategies, and ensuring that the package was an effective way to communicate information about the strategies to teachers prior to its distribution in the community. Not only did this study 
elicit constructive feedback from individual teachers, it also provided further insights into the complexities of the implementation process.

\section{Visual Schedules and Work Systems}

Visual schedules and work systems have been used since the 1970s as part of the structured teaching approach associated with the Treatment and Education of Autistic and Related Communication Handicapped Children (TEACCH) program (Carnahan, Harte, Schumacher, Hume, \& Borders, 2011; Mesibov, Howley, \& Naftel, 2016). Students on the autism spectrum can have difficulty with small changes or transitions (American Psychiatric Association, 2013). Visual schedules help to orient students, and prewarn them of changes, by providing a visual representation of a sequence of events (e.g. a timetable). Schedules can consist of pictures, photos, symbols, or text, depending on the individual needs of those using them (Hume, 2015). Visual schedules have been researched extensively and have been shown to have a positive impact on the ability of students on the spectrum to stay on task (Knight, Sartini, \& Spriggs, 2014; Lequia, Machalicek, \& Rispoli, 2012). Similar to visual schedules, work systems visually break down tasks into elements allowing students to clearly see what they have to do and self-monitor their progress. A work system provides students with visual information about (a) what to do (b) how much to do (c) how to know they are finished, and (d) what to do next (Howley, 2015). Work systems have been the focus of only a small number of studies involving school aged children, but, like visual schedules, have been demonstrated to be effective in supporting students on the spectrum to transition between task elements and stay on task (Hume \& Odom, 2007; Hume, Plavnick, \& Odom, 2012; Mavropoulou, Papadopoulou, \& Kakana, 2011; O'Hara \& Hall, 2014).

Visual schedules and work systems can be adapted to a general education classroom setting (Hume, 2015; Hume, Sreckovic, Snyder, \& Carnahan, 2014; Mesibov et al., 2016), and many teachers may already use elements of this sort of visual structure throughout the day. 
However, published research on their use in supporting students on the autism spectrum in general education settings is scant, and has featured interventions implemented by researchers, or special education teachers, in isolation from the rest of the class (Hume, et al., 2012). The study preceding this one evaluated the implementation of visual schedules and work systems by classroom teachers using a whole-class approach and found they had a positive impact on the ontask behaviours of students on the spectrum (citation withheld for current blind review). This study used a workbook (citation withheld for current blind review) that was later adapted to become a professional development package called Finished! The On-task Toolkit. The toolkit provided information about structured teaching, visual schedules, and work systems, as well as instructions for their implementation, examples, and optional templates.

While there was preliminary evidence for the effectiveness of the package, the need to address the potential research to practice gap required an examination of its broader application in classrooms outside of controlled research conditions, with diverse students undertaking various activities. Observations during the previous study were restricted to particular times and contexts and the instructions given to teachers were specific to the task observed. Given that structured teaching strategies might be useful throughout the school day and may have an impact on the well-being of students on the spectrum more generally (Howley, 2015), further research is warranted to determine the utility and social validity of the toolkit.

Both Howley (2015) and Knight et al. (2014), in their reviews of the literature on structured teaching and visual schedules, identified a lack of measures showing generalisation to other contexts as a limitation in many studies. In both cases, the authors also noted the need for a deeper investigation of social validity. While many studies have included a social validity measure, these are generally limited in scope and number of participants (Howley, 2015). It is, however, very important to take the views and experiences of intended users into account when 
researching interventions with the intention of facilitating sustainable implementation (Dingfelder \& Mandell, 2011; Parsons et al., 2013).

\section{From Research to Implementation}

Dearing (2009) provided a "top 10" list of mistakes that are made in the dissemination of social science research. The first is the common assumption that the evidence provided by researchers is central to whether or not a practice is adopted. Dearing (2009) listed variables such as compatibility, simplicity and cost as examples of other factors influencing whether an intervention is adopted or not. For teachers, there are many potential barriers to implementing new evidence-based practices. The pressures of time, workload, and limited training or resources may all negatively impact the uptake of research findings (Forlin, 2001; Forlin, Keen, \& Barrett, 2008; Kyriacou, 2001). Additionally, teachers' knowledge of practices, and confidence in the ability to implement them - i.e. self-efficacy - are important factors in their successful implementation (Damschroder et al., 2009; Fixsen, Naoom, Blase, \& Friedman, 2005). Discourse on the research to practice gap in autism and special education invariably leads to recommendations that researchers communicate, collaborate, or engage with teachers to ensure that research outcomes are relevant and useful in classroom contexts (Dykstra Steinbrenner et al., 2015; Kasari \& Smith, 2013; Parsons et al., 2013).

The aim of the study was to ascertain the views of general education primary school teachers regarding the use of visual schedules and work systems as described in Finished! The On-task Toolkit, and to obtain their feedback on the utility of the toolkit in assisting teachers to implement these strategies in their classrooms. Specifically, the primary questions this study aimed to address were:

- What were teachers' views on the toolkit?

- Did their knowledge of, and confidence using, visual schedules and work systems change after reading the toolkit? 
- What were the experiences of those that did go on to implement the strategies?

\section{Method}

\section{Study Design}

A mixed methods approach was used across two phases in the current study. In phase one, a two-part survey was used to assess teachers' responses to Finished! The On-task Toolkit and the strategies it outlines. In phase two, a qualitative case study approach was used to obtain further feedback about the use of the strategies outlined in the toolkit, and to capture the complexity and richness of the classroom (Yin, 2014). Teachers who had participated in phase one were invited to implement the strategies outlined in the toolkit and participate in semistructured interviews about their experience. Ethics approval for the study was granted by [name withheld for review] ethics committee (No. to be provided). Approval was also obtained from relevant educational authorities and, where required, from other groups involved in the distribution of survey information.

\section{Phase One}

Participants. Forty-one Australian primary school teachers with between 1 to 35 years of experience agreed to participate and commenced the online survey. All 41 completed part one of the survey with 22 going on to begin part 2 . Three of those 22 teachers were excluded from part 2 of the survey, leaving 19 who completed both parts. Preliminary demographic questions on part one of the survey revealed that teachers who volunteered to take part generally had experience with students on the autism spectrum, and had some professional training in this area. Only four of the 41 teachers who completed part one of the survey had no training relevant to teaching students on the spectrum, and most had received professional development from more than one source. School-based professional development had been available to 26 of the teachers, 21 had participated in on-line training, 15 reported attending workshops, and 15 had attended conference sessions. The extent of the teachers' professional knowledge was reflected in the practices that 
they already had in place to support students on the spectrum, with 28 participants explicitly listing visual schedules or timetables. Four teachers mentioned task analysis, or breaking down tasks, and two more were using approaches based on the TEACCH program. Other popular strategies included timers, sensory interventions, social stories, and other visual supports. Most teachers ( 37 of the 41 respondents) identified transitions, staying on task, and working independently as challenges for their students.

Materials. Finished! The On-task toolkit. (citation withheld for current blind review) consisted of four sections that included information and guidance for implementation: (a) background information about structured teaching with links to online information and videos about the TEACCH program, (b) key information about using structured teaching strategies in general education classrooms, including the importance of taking an inclusive approach to implementation, (c) information about visual schedules with visual examples, instructions for implementation, templates, and a pull-out "at a glance" fact sheet, and (d) information about work systems, including instructions for implementation, examples, templates, and a pull-out "at a glance" fact sheet. Also included was an implementation checklist for both visual schedules and work systems.

Online survey. The survey was conducted using SurveyMonkey Premium. The two parts were linked using the participants' email addresses, which were later removed to de-identify data prior to analysis. The survey was designed to assess teachers' engagement with, and response to, the toolkit, their views on the strategies it described, and changes to their knowledge and confidence with respect to visual schedules and work systems after viewing the toolkit. The survey included multiple choice and open questions, but, for the most part, used seven-point Likert scale questions. Part one collected participants' demographic information; asked them about teaching strategies that they currently used; and recorded their knowledge of, and confidence using, both visual schedules and work systems. Part two of the survey recorded 
information about the way in which teachers responded to the resource itself - i.e. whether they read each section or followed links to other information, whether they thought the resource was useful, and, although survey respondents were not asked to implement anything in their classrooms, whether they believed the strategies themselves would be useful. Teachers were also asked to rate their knowledge and confidence regarding visual schedules and work systems since viewing the toolkit.

Procedure. A flyer with information about the survey was distributed to teachers through a number of professional organisations, teachers' unions, and through social media. The flyer and participant information was also distributed through government schools in several states, and Catholic and independent schools. Teachers wishing to participate were then sent a link to part one of the survey. On completion of part one, participants were given a link to Dropbox where they were able to download a digital copy of Finished! The On-task Toolkit. After a minimum of two weeks to allow them time to review the package, teachers were emailed a link and asked to complete part two of the survey.

Data analysis. Data was downloaded from SurveyMonkey ${ }^{\mathrm{TM}}$ (www.surveymonkey.com) into the Statistical Package for the Social Sciences (SPSS; IBM Corp, Released 2016) where responses were de-identified. Descriptive analysis was used to assess teachers' responses to the toolkit, and views about the usefulness of the strategies. The Wilcoxon signed rank test was used to make a comparison between questions in part one and part two which asked participants about their knowledge of visual schedules and work systems, and their confidence using these strategies.

\section{Results: Phase One}

Teachers' views on the toolkit. Of the 22 teachers who went on to begin the second part of the survey, 3 had not read any of the toolkit and were excluded from further analysis. Two of the 19 remaining did not read the toolkit in its entirety, but completed the survey basing responses 
on what they had read. When asked to rate items on a seven-point scale $(1=$ very difficult, $4=$ neither difficult nor easy, 7 = very easy), most of the 19 respondents indicated that they found all four sections of the toolkit easy, or very easy, to follow (mean $=5.95-6.37$, range 3-7). Respondents were also asked to rate how useful they found different elements of the toolkit on a scale of one to seven $(1=$ not useful at all, $4=$ somewhat useful, $7=$ very useful $)$. Apart from a single outlier in a few cases, respondents indicated that the different elements of the toolkit were somewhat to very useful (see Table 1). The strategies outlined in the toolkit were considered to be useful and easy to implement by most of the teachers, however visual schedules were regarded more favourably than work systems, with 15 respondents saying that they would be very likely to use visual schedules compared to eight who said they would be very likely to use work systems (see Table 2).

Changes in teachers' knowledge and confidence. The survey asked teachers to rate their knowledge of, and confidence using, visual schedules and work systems, before and after reading the toolkit. As presented in Table 3, there was a non-significant increase in teachers' selfreported knowledge regarding visual schedules and work systems after reading the toolkit. There was a statistically significant increase in teachers' self-reported confidence in using visual schedules $(\mathrm{Z}=-2.543, p=.011)$, and the improvement seen in confidence in using work systems was also statistically significant $(\mathrm{Z}=-2.708, p=.007)$.

\section{Phase Two}

Participants. Four teachers who had completed both parts of the survey, and who had indicated an interest in participating in follow-up qualitative interviews, agreed to participate in the second phase of this study. All the teachers worked within government schools, three taught Year 1 classes (second year of formal education), and the other was a special education teacher working with students in different year levels within a general education school. Demographic 
information relevant to the study are presented in the qualitative vignettes that capture their experiences below.

Procedure. The four participants were familiar with the toolkit from completing the survey, and some had already either begun to implement the strategies in their classes, or to reflect on similar strategies that they had already put in place. They were given a further three weeks after agreeing to participate to trial visual schedules and work systems in their classrooms prior to interview. The teachers had sole responsibility for the extent and way in which the intervention was implemented and had been provided with a checklist to monitor their own fidelity to the intervention should they wish. The interviews were semi-structured and ran from 38 minutes to 75 minutes. Participants were asked for information about the classes they taught, the strategies they were already using, how they implemented the strategies described in the toolkit, how their students responded, and what they thought about using the strategies. They were also asked for feedback on the toolkit itself and how it could be further developed and disseminated. Interviews were all conducted over the telephone and, with the participants' permission, recorded for analysis.

Data analysis. Halcomb and Davidson (2006), suggest that due to the technical difficulties associated with transcription and its role in generating meaning, the need for verbatim transcription of interview data should be questioned. In alignment with this perspective, complete transcripts of the interview recordings were not used in this study. Following the process Halcomb and Davidson (2006) outline, field notes were made during the interviews and revisited with subsequent reviewing of the recordings. The content of each interview was organised according to the same thematic structure, addressing the teacher's implementation of visual schedules, their implementation of work systems, their views on how these might work as wholeclass or inclusive practices in general education classrooms, and feedback and recommendations regarding the toolkit itself. Transcriptions were made of salient quotes and illustrative points. The 
participants' accounts were summarised in a short, narrative vignette form, as suggested by Yin (2014) for the purpose of combining multiple cases in a mixed methods design. This narrative approach to interpreting interview data necessarily involves the co-creation of meaning through the interaction of participant and interviewer (Polkinghorne, 2007), and so would not gain further authority from external reliability checks However, a substantial length of time was devoted to each interview to ensure that the resulting understanding of participants' views and experiences had validity.

\section{Results: Phase Two}

The following four case study vignettes describe the reported experiences of teachers who trialled the strategies described in the toolkit, and their views on its implementation. Names used are all pseudonyms. All four teachers had completed the survey and were recruited to trial the toolkit during the last term of the school year. Interviews took place at the end of the school year.

Case study one. Kathy was a Year 1e teacher (second year of formal education) with a class of 25 students. She had one student with a diagnosis of autism who had been gradually transitioning to general education schooling from an autism specific setting by attending each setting part-time. He had difficulty staying on task and with transitions and changes to his routine.

Visual schedules. Kathy reported that she had been using a daily timetable since the beginning of the year with some success, and that its use had been driven by the needs of her student on the spectrum. "The thing that we do anyway, and that is supported in the tool kit, is the visual timetable" she said, "We made sure we did because he was coming into the classroom". However, although visual schedules were already in use, she claimed that the toolkit had enhanced her understanding of the strategy and led her to refine the way in which they were used. "I think we went a bit too complex," she said, "we threw a bit too much at him."

When we started the year, he had the class one on his desk with what he had to do and then what is reward was... as the year went on he didn't need that as much, so he just 
using the class timetable. And I guess because he's more integrated in the class in that he is engaging with the curriculum ...This term we've been much more successful keeping him engaged... He's just come along so much., I think because the structure in the toolkit too and the things we've done with him in here, are very simple and clear, and he knows exactly what's going on and where he's supposed to be.

Kathy said she had simplified what she was doing, used more visuals and was relying less on giving verbal instructions, which she felt were not always taken in by her student on the spectrum. According to Kathy, the schedule helped her student, who was often non-verbal when stressed, become more talkative. "He would instigate conversation, which he hadn't been doing" Kathy reported, "Now he's really much more verbal. He'll ask questions about the timetable in the morning... or if something's missing he'll tell me."

Work systems. Kathy said that she had previously tried using a work system similar to the ones used in the autism specific setting, with just her student on the spectrum, however he did not respond well to this. Kathy noted that he did not like being isolated from the other students, and, although he required some modification to the classwork, he preferred to be working on the same curriculum. After reading the toolkit and linked information however, work system elements were incorporated into visual supports for the whole class such as a visual display that students could check at any time to know where they were supposed to be and what they needed for that activity:

I'll draw pictures of the scissors and things that they need - the equipment they need and it's always the same board that it's written up on...If they don't know what they're doing or what they need it's up there, and that's all of them, not just [the student on the spectrum] because a lot of them don't know and their sitting there. You think they know but they don't. 
Whole-class implementation. The inclusive, whole class approach promoted in the toolkit worked well, Kathy reported. Visual schedules, she claimed, worked with all of the students. "All the children are more engaged," she said. She noticed faster transition times for all students, and this was also beneficial for the student on the spectrum. Kathy observed, "What has been good for [the student on the spectrum] ...those transitions are difficult for him, but the noise is less and the kids are quicker to get ready." She would recommend these strategies to other teachers, she stated, and continue to use them even if she had a class without any students on the spectrum.

Feedback and recommendations on the toolkit. Kathy said that finding time to just read the toolkit was a challenge and that this could be an issue for teachers. As Kathy put it, "If I don't have a need to know what you're telling me, I'm not going to connect with it". Kathy responded positively to the toolkit itself, noting that focusing on just the two strategies and basic information made it accessible to busy teachers. She suggested including examples of visual schedules and work systems for each year level and signalled that she thought video modelling and further faceto-face professional development might be effective ways of communicating this approach to teachers. Kathy described herself as "not very techie" and reported that she was unsure about the idea of using technology to implement the strategies.

Case study two. Like Kathy, Trudy was a Year 1 teacher. She had two students with ASD diagnoses in her class of 22.

Visual schedules. Trudy already used visual timetables in her classroom. She said she had taught students on the spectrum previously and was aware that visual schedules were helpful for them, and for teaching in early childhood more generally. In the year of the current study, however, she had changed the way in which she was using schedules as she felt that her students on the spectrum required more consistency: 
I did up a visual timetable that was... for each day of our week. That was laminated at the beginning of the year... [A student on the spectrum] would help me put them up on the board and then we had a little frog magnet that he moved to say where we were up to. And then on the days that he was stressed or there had been something happen at home where his constant had been moved, he would be very much saying, "May I go and move the frog now? You're not doing this, we need to be doing that". So, he needed that at the beginning of the year very much... I kept everything as constant as I could.

While she had initiated these changes prior to receiving the toolkit, she subsequently reflected on the way in which she had implemented visual schedules, She made the schedules very simple "to keep the visual noise down" and, later in the year, she transitioned the class to written timetables, involving students in writing the timetables themselves. She said she found this valuable for reinforcing literacy skills:

I think because we had the constant all year with our timetable, then now weaning them this term onto just a written one that they're involved with writing often... - because they can read now, they're adequate readers, it reinforces all of their literacy skills as well - I can put changes in without too much of a problem.

Work systems. After reading the toolkit, Trudy had trialled work systems by breaking down tasks and found the approach useful. However, she reported that the strategy was not as helpful for her students on the spectrum as it was for the rest of the class. Work systems increased on-task behaviour in other class members, but she said her students on the spectrum were unsettled due to end of year changes to their routine. "I think with all of the change at this time of year," she said,

I have to be very much with those two, so it was a bit difficult to gauge how helpful it was. I suspect that had it been introduced, and I think I will try this - certainly I will try 
this - next year, is to start it early in the year so it becomes part of our routine. Introducing a new behaviour to our routine is probably why those two didn't engage in it so much. Trudy noted that one of those students had, however, constructed an individual work space for himself similar to those used in the TEACCH program, suggesting that such strategies might be helpful at other times

Whole-class implementation. Trudy said she would have liked to create similar work spaces for other students but did not have the room. "I don't know whether it would be practical to have it set up all the time in a classroom setting" she said. In the new year, however, Trudy was intending to use the strategies as a whole class approach regardless of whether she had students on the spectrum in her class or not. "All classes, regardless of age, should have some sort of visual cueing system and regardless of whether you have somebody on the spectrum or not" she said.

Feedback and recommendations on the toolkit. Trudy noted the need for different resources for different age groups with students in the early years needing more support to learn the skills required to work independently. Classroom space was a challenge for Trudy, and an issue in her school more generally. Like Kathy, she reported holding conflicting views about the idea of implementing visual schedules and work systems using technology. "The jury is still out with me," she said. She suggested that information for parents would be useful, and web-based resources would be helpful, if principals and teachers were aware they were there. She suggested that it would be useful to have a place where teachers could share what they had done and what had worked well. Like Kathy, Trudy said she liked the idea of further professional development, noting that "it really needs to be part of our training at university".

Case study three. Marie was also a Year 1 teacher with a class of 26 children. Three of her students were on the autism spectrum and she was anticipating having four students on the spectrum in her class the following year. She noted that the school where she taught had a 
reputation in the community for having a "good [special education] unit" and had many students with identified support needs. She had also undertaken postgraduate study in autism.

Visual schedules. As with Kathy and Trudy, Marie was already using a whole class timetable. She also employed other visual supports like colour coding of books, organising equipment and using visual communication tools to help with emotional regulation. "I was using more kind of the organisation of equipment" she said, "but not to the extent of the TEACCH".

According to Marie, the positive effects of using a visual schedule were evident when it was changed or removed. "When you suddenly have to have a rush assembly and you don't do the schedule... they get very anxious," she observed.

Work systems. Marie had implemented further structure around classroom activities since receiving the toolkit. She reported following the links to further information and videos in the toolkit and becoming familiar with the TEACCH program. "I've used parts of it, obviously" she reported,

but I'm lucky too, because I have a double classroom space for one class, so I could create all these different areas easily which I hadn't done before so... and extremely effective, Yeah, very pleased, so I'm going to continue this next year.

Whole-class implementation. It was not just Marie's students on the spectrum who were keen to use the areas she set up. "Some of the children ask to use the quieter work station areas too," she said, "and I felt like I didn't have enough space, but now I've set up my whole room." She found this approach successful in helping many of her students to stay on task and work independently. The children were giving me feedback," she reported, "saying 'nobody's disturbing me and I can actually concentrate"”. Work systems and visual schedules would be a part of Marie's future teaching practice, she claimed, whether or not she had students on the spectrum in her class: 
The more I learn, the more I put into place in class and then I kind of see what the others... like if I forget to do the visuals one day then I see some other children slightly falling apart and getting quite confused and anxious, "What are we doing next?" or, "You haven't done it yet? Why haven't you done it yet?” and, “I don't know what we're doing after morning tea." Yeah, really interesting.

Feedback and recommendations on the toolkit. The greatest challenge Marie faced in implementing the strategies described in the toolkit, she said, was sourcing equipment like the furniture and room dividers she used to make individual work spaces. However, she noted that there would have been ways to manage with limited resources. For other teachers, she thought, the barriers to using these strategies would more likely be related to a lack of training and a limited understanding of the needs of students on the spectrum. "There are still a group of teachers who don't want to know about autism, and don't want to make any changes for autism," she said. Marie was enthusiastic about the idea of further face-to-face professional development on the use of the strategies outlined in the toolkit, "because people can ask questions, and teachers ask lots of questions". She was positive about technology-based implementation as she reported that her class was well resourced with a set of iPads. However, she said she found the physical manipulation of materials more effective.

Case study four. In contrast to Kathy, Trudy and Marie, Jenny was not a classroom teacher. She was a special education teacher in a general education primary school supporting students across all year levels. She worked mainly in the classroom but withdrew students from the classroom at times when they needed a break. She worked with six students on the autism spectrum ranging from five to ten years old.

Visual schedules. As she was not involved in the general running of the classroom, Jenny was not involved in implementing visual schedules, but she noted that most classrooms in the 
school did use them to some degree. Some of the children she worked with had individual visual schedules that were used to provide structure to lunch breaks, and these worked well.

Work systems. Since receiving the toolkit, Jenny focussed on creating a work system for a Year 2 student on the spectrum who spent a large part of each day in the special education unit, and rarely did any work.

A big battle for me was trying to work out number one how can I get these kids to stay in class and to stay on task? And help the teachers with that. This particular child, last year, spent a lot of time out of class. At the start of this year, this kid would spend a lot of time in the corner of the class playing games because they just didn't want to do the work. Jenny used a box with numbered folders to break down tasks, and initially used a reward of "free time" to motivate the student to use the system. "What I did with him" she explained, is there was a station where there was one, two, three tasks to do and as he did each one he would move the little Velcro number to the finished column, and he loved it because it was work that was at his ability, it was work that was not too challenging for him.

After a while, the student reportedly stopped asking for the reward and started asking for more work to do. "It was good because I would come in there, and he would finish them," Jenny said,

he would move them over and then he'd come up and say, "Come on, you've got to refill those, refill those." ... He ended up chasing me up, bringing me the folders, and saying, “Can you give me more work, more work?"

She was conscious of making the system simple so that classwork, differentiated by the teacher, could be used. "It had to be something, obviously... that the teacher could eventually implement" she said.

Whole-class implementation. Jenny aimed to continue using work systems as a way to facilitate inclusion of the students she was supporting in the general education classrooms. 
Previously, Jenny said, the unit was used mostly for withdrawal with students spending hours there each day. "The teachers at this school, some teachers, were very good at differentiating, but were made to feel that they weren't in charge of the ASD kids, or the verified kids - that was SEP [special education program]" Jenny noted. The SEP had focussed on developing social and emotional skills and students were missing out on classwork. As Jenny put it, "SEP time was just play time". Jenny viewed work systems as a useful tool for getting her students back in the classroom.

If you have a system like this in place, it does mean that you don't have to spend so much time directing these students. You can have them learning, you can have them doing work, and you don't have to be babysitting them all the time.

Jenny thought that something similar to the work system she created could be used to scaffold learning for the class more generally and said that she would recommend the use of these strategies regardless of whether there were students in the class with diagnoses of autism.

Feedback and recommendations on the toolkit. Jenny liked being able to access further information following the links but thought that the time needed to sit down and watch videos could be a barrier to teachers accessing the supplementary information.

You can't have everything there in the one place. I thought the book was really, really well designed, and it sets you up, if you have the time, to go on and then build on that. I think the links... were great... [but] I would like it if you did all the work for me... and then all I had to do was print things out and laminate it.

Jenny was of the opinion that special education support teachers, such as herself, were ideally placed to communicate these ideas to teachers, who often did not have time to research and develop resources. Having a way to share these ideas within the school would be helpful. Jenny was enthusiastic about the idea of using technology to implement work systems in her school. Her suggestions for further development of the toolkit included providing some sort of 
information sharing space for teachers (e.g. a blog, webpage, or a group email). "You could have pictures of things" she said, "and teachers could talk about how they're using things". Workshop style professional development, or school visits where the strategies could be demonstrated, would be very useful she said, and could provide an opportunity to deliver more detailed information and show videos, "PD now and then would be great," she remarked, "the teachers love it".

\section{Discussion}

The present study sought to assess teachers' views on Finished! The On-task Toolkit, to ensure that it can be a suitable resource for use by general education teachers to help support their students on the spectrum. While research into the strategies the toolkit describes has provided some evidence that they are effective, this does not ensure their translation to classroom practice. As McIntyre (2005) puts it, "the kind of knowledge that research can offer is of a very different kind from the knowledge that classroom teachers need to use" (p. 359). The findings of this study suggest that the toolkit itself may be well regarded by teachers, and the strategies it describes may be considered useful. However, aspects of the study can be seen to highlight some of the challenges involved in translating research to practice and indicate that providing teachers with further information and support may be helpful in facilitating the implementation process.

\section{Teachers' Views on the Toolkit}

Both the survey and the interviews aimed to discover, initially, how teachers viewed the toolkit. The 19 teachers who provided feedback on the toolkit in part two of the online survey were overwhelmingly positive in their responses. They found the toolkit easy to follow and indicated that they felt that the strategies would be useful in their classes for both students on the spectrum and students without autism diagnoses. There were no particular elements of the toolkit that were identified as unhelpful. There was though, a discernible difference between responses regarding the implementation of visual schedules and work systems. A large proportion of survey 
respondents, and all three of the classroom teachers interviewed, had indicated that they were already using visual schedules to support their students on the spectrum. Others may have already been using daily schedules or timetables in their classes without an awareness of how, or why, they are effective with students on the spectrum (Knight et al., 2014). This familiarity with visual schedules may be the reason that respondents seemed to consider them to be easier than work systems to implement and would be more likely to use them despite, perhaps, gaining more from information on the less familiar strategy.

Work systems were defined broadly in the toolkit and it included a number of diverse examples such as individual work spaces, task checklists, and task information provided via assistive technology. Teachers trialling the toolkit reported different ways of implementing work systems depending on the space and resources they had available, and the needs of their students. It seems that the variability of classroom environments and student cohorts necessitates that school-based interventions be adaptable. Teachers are likely to discontinue, or alter, rigidly outlined practices, whereas in-built adaptability could promote implementation and lead to higher levels of fidelity (Damschroder et al., 2009; Dearing, 2009).

The four teachers who trialled the toolkit in phase 2 of this study continued to regard it positively, but when asked about possible recommendations for further enhancing teachers' understanding of the strategies, they were each keen to see other forms of support provided, such as video modelling and face-to-face professional development. They identified a number of potential barriers to engaging with the toolkit. These included:

- Time/workload

- $\quad$ Space

- Resources (e.g. furniture, dividers)

- Lack of knowledge/professional development 
These barriers correspond to some of those identified by Saggers et al. (2015) and, more generally, Fixsen et al. (2005). Lack of time, or a heavy workload, has been shown to be a leading factor in teachers' concerns about inclusion in a number of studies (Round, Subban, \& Sharma, 2016; Soto-Chodiman, Pooley, Cohen, \& Taylor, 2012), While the idea of built-in adaptability may help to ensure an intervention can be tailored to suit the environment, if teachers do not have the time to read and apply an intervention, the idea of making adaptations may seem particularly onerous. Two of the suggestions made by teachers during this study could be helpful in addressing this issue: the idea of having a platform for peers to share information about workable applications, and the idea of specialised teachers acting as a "communication link" (Fixsen et al., 2005) between researchers and teachers. While, in the current study, the toolkit was intended to be concise, teachers' feedback clearly indicated that they felt the use of other modes of communication, in addition to print, would enhance their ability to access and understand this information efficiently.

\section{Changes in Teachers' Knowledge and Confidence}

Those who completed the survey reported a significant change in their confidence levels with respect to using both visual schedules and work systems. That there was less change in selfreported levels of knowledge about the strategies could be due to how well informed the cohort was to begin with. However, it may be that this knowledge was theoretical, and that the examples and instructions in the toolkit provided a practical guide to utilising this knowledge. While causality cannot be determined in the current study due to the small number of participants, these measures indicate a possible relationship between the intervention materials and teacher selfefficacy concerning providing support for students on the spectrum. This confidence, or selfefficacy, as mentioned earlier, is a crucial factor in behavioural change and a precondition for successful implementation (Damschroder et al., 2009; Fixsen et al., 2005). 


\section{Implementing the Toolkit}

All of the teachers trialling the toolkit in classrooms had some level of success with implementing the strategies, and all were keen to continue using them again in the following year regardless of whether they had students on the spectrum in their classes. While these strategies had been implemented during the earlier multiple-baseline study (citation withheld for current blind review), the current study has shown that teachers were able to use the toolkit to implement the intervention independently as part of their day-to-day teaching practice. Additionally, both strategies were considered to be useful, or potentially useful, for students not on the autism spectrum. In fact, in one case, work systems were found to be more helpful for these students than for the students on the spectrum.

\section{Limitations}

The most obvious limitation of this study was the small number of teachers to express an interest in taking the online survey, and, following on from that, the large number of teachers who completed part one but did not follow up to complete the survey. However, this limitation is, perhaps, indicative of some barriers to translating research to practice. Engaging teachers in research is, unsurprisingly, a challenge, due largely to the many demands teachers have upon their time. Despite efforts to distribute information about this survey as widely as possible, the number of teachers offering to take part remained small, with almost half failing to complete the second part. Those who did participate tended to have a high level of professional interest in the subject of autism. While the expertise of these teachers has resulted in valuable feedback, the survey did not seem to reach those for whom the toolkit may have been most useful. As Kathy observed, without "a need to know" teachers may not seek out, or spend time learning about, effective strategies for supporting students on the spectrum.

While there is growing recognition among researchers that involving teachers in the research process is an essential element in developing interventions that are both based on 
evidence and readily translated to real-world settings (Abbott, Walton, Tapia, \& Greenwood, 1999; Parsons et al., 2013), there is, perhaps, little incentive for teachers to become involved in projects not immediately relevant to their specific teaching practice. Giving consideration to teachers' workloads during the research design phase is, of course, to be recommended, however, teachers' working conditions are influenced by larger organisational and societal systems, and concomitant issues concerning time management are, to a large extent, intractable. As things stand, though their numbers are small, teachers who do self-select to be involved in research might play a critical role in the implementation process by taking on roles of "early adopters" (Fixsen et al., 2005) or “innovators" (Dearing, 2009).

Technical issues may also have had an impact on the numbers to complete part two of the survey, with the email links and reminders generated by SurveyMonkey ${ }^{\mathrm{TM}}$ being filtered as spam by some email servers, and not being received by the survey participants. Attempts were made to counter this by sending further, personal reminder emails, however this did not lead to a noticeable rise in responses. Teachers were also unable to access file sharing sites through some institutional internet servers, and so some teachers had difficulty downloading the toolkit from Dropbox $^{\mathrm{TM}}$. Again, this technical issue was countered by emailing the toolkit as a pdf attachment to teachers who had completed part one. An awareness of this type of potential barrier to communication with teachers may allow other researchers to avoid similar pitfalls.

\section{Conclusion}

With the lag in evidence-based interventions making their way into classrooms, there is a need to give consideration to issues of implementation during the research process. Research findings do not necessarily, nor automatically, translate to effective practice (Dearing, 2009; Dingfelder \& Mandell, 2011). By engaging general education teachers to share their views on both intervention strategies and the information package in which they are outlined, this study 
aimed to ensure that the intervention would be of practical, sustainable use in various general education classroom settings.

\section{References:}

Abbott, M., Walton, C., Tapia, Y., \& Greenwood, C. R. (1999). Research to practice: A" blueprint" for closing the gap in local schools. Exceptional Children, 65(3), 339.

American Psychiatric Association. (2013). Diagnostic and statistical manual of mental disorders (5th ed.). Arlington, VA: American Psychiatric Publishing.

Ashburner, J., Ziviani, J., \& Rodger, S. (2010). Surviving in the mainstream: Capacity of children with autism spectrum disorders to perform academically and regulate their emotions and behavior at school. Research in Autism Spectrum Disorders, 4(1), 18-27. doi:10.1016/j.rasd.2009.07.002

Australian Bureau of Statistics. (2016). Disability, Ageing and Carers: Summary of Findings, 2015 (cat. no. 4430.0). Retrieved from http://www.abs.gov.au/ausstats/abs@.nsf/mf/4430.0.

Autism Awareness. (2014). \#autism2014: A national survey of autism parents and carers. Summary report. Retrieved from http://www.autismawareness.com.au/uploads/Autism2014_Survery_Summary_Report_f or_AAA.pdf.

Carnahan, C., Harte, H., Schumacher, K., Hume, K., \& Borders, C. (2011). Structured work systems: Supporting meaningful engagement in preschool settings for children with autism spectrum disorders. Young Exceptional Children, 14(1), 2-16.

Cook, B. G., \& Odom, S. L. (2013). Evidence-based practices and implementation science in special education. Exceptional Children, 79(2), 135-144.

Damschroder, L. J., Aron, D. C., Keith, R. E., Kirsh, S. R., Alexander, J. A., \& Lowery, J. C. (2009). Fostering implementation of health services research findings into practice: a 
consolidated framework for advancing implementation science. Implementation science, $4(1), 50$.

Dearing, J. W. (2009). Applying Diffusion of Innovation Theory to Intervention Development. Research on Social Work Practice, 19(5), 503-518. doi:doi:10.1177/1049731509335569

Dingfelder, H. E., \& Mandell, D. S. (2011). Bridging the research-to-practice gap in autism intervention: An application of diffusion of innovation theory. Journal of Autism and Developmental Disorders, 41, 597-609. doi:10.1007/s10803-010-1081-0

Dykstra Steinbrenner, J. R., Watson, L. R., Boyd, B. A., Wilson, K. P., Crais, E. R., Baranek, G. T., ... Flagler, S. (2015). Developing Feasible and Effective School-Based Interventions for Children With ASD: A Case Study of the Iterative Development Process. Journal of Early Intervention, 37(1), 23-43. doi:10.1177/1053815115588827

Fixsen, D. L., Naoom, S. F., Blase, K. A., \& Friedman, R. M. (2005). Implementation research: a synthesis of the literature.

Forlin, C. (2001). Inclusion: Identifying potential stressors for regular class teachers. Educational Research, 43(3), 235-245.

Forlin, C., Keen, M., \& Barrett, E. (2008). The concerns of mainstream teachers: Coping with inclusivity in an Australian context. International Journal of Disability, Development and Education, 55(3), 251-264.

Halcomb, E. J., \& Davidson, P. M. (2006). Is verbatim transcription of interview data always necessary? Applied Nursing Research, 19(1), 38-42. doi:10.1016/j.apnr.2005.06.001

Hill, E. L. (2004). Executive dysfunction in autism. Trends in Cognitive Sciences, 8(1), 26-32. doi:10.1016/j.tics.2003.11.003

Howley, M. (2015). Outcomes of structured teaching for children on the autism spectrum: does the research evidence neglect the bigger picture? Journal of Research in Special Educational Needs, 15(2), 106-119. doi:10.1111/1471-3802.12040

Hume, K. (2015). Structured Teaching Strategies: A Series. Retrieved from http://www.iidc.indiana.edu/?pageId=3520

Hume, K., Loftin, R., \& Lantz, J. (2009). Increasing independence in autism spectrum disorders: A review of three focused interventions. Journal of Autism and Developmental Disorders, 39, 1329-1338. doi:10.1007/s10803-009-0751-2

Hume, K., \& Odom, S. (2007). Effects of an individual work system on the independent functioning of students with autism. Journal of Autism and Developmental Disorders, 37, 1166-1180. doi:10.1007/s10803-006-0260-5 
Hume, K., Plavnick, J., \& Odom, S. L. (2012). Promoting task accuracy and independence in students with autism across educational setting through the use of individual work systems. Journal of Autism and Developmental Disorders, 42, 2084-2099. doi:10.1007/s10803-012-1457-4

Hume, K., Sreckovic, M., Snyder, K., \& Carnahan, C. R. (2014). Smooth transitions: Helping students with autism spectrum disorder navigate the school day. Teaching Exceptional Children, 47(1), 35-45. doi:10.1177/1098300709332346

Humphrey, N., \& Lewis, S. (2008). "Make me normal": The views and experiences of pupils on the autistic spectrum in mainstream secondary schools. Autism, 12(1), 23-46. doi: $10.1177 / 1362361307085267$

IBM Corp. (Released 2016). IBM SPSS Statistics for Windows (Version 24.0). Armonk, NY: IBM Corp.

Kasari, C., \& Smith, T. (2013). Interventions in schools for children with autism spectrum disorder: methods and recommendations. Autism, 17(3), 254-267. doi:10.1177/1362361312470496

Knight, V., Sartini, E., \& Spriggs, A. D. (2014). Evaluating visual activity schedules as evidencebased practice for individuals with autism spectrum disorders. Journal of Autism and Developmental Disorders, 45(1), 157-178. doi:10.1007/s10803-014-2201-z

Kyriacou, C. (2001). Teacher Stress: Directions for future research. Educational Review, 53(1), 27-35. doi:10.1080/00131910120033628

Lequia, J., Machalicek, W., \& Rispoli, M. J. (2012). Effects of activity schedules on challenging behavior exhibited in children with autism spectrum disorders: A systematic review. Research in Autism Spectrum Disorders, 6(1), 480-492. doi:10.1016/j.rasd.2011.07.008

Mavropoulou, S., Papadopoulou, E., \& Kakana, D. (2011). Effects of task organization on the independent play of students with autism spectrum disorders. Journal of Autism and Developmental Disorders, 41, 913-925. doi:10.1007/s10803-010-1116-6

McIntyre, D. (2005). Bridging the gap between research and practice. Cambridge Journal of Education, 35(3), 357-382.

Mesibov, G. B., Howley, M., \& Naftel, S. (2016). Accessing the curriculum for learners with autism spectrum disorders: Using the TEACCH programme to help inclusion (2nd ed.). Abingdon, Oxon: Routledge.

National Autism Center. (2015). Findings and conclusions: National standards project, phase 2. Randolph, Massachusetts: Author. 
O'Hara, M., \& Hall, L. J. (2014). Increasing engagement of students with autism at recess through structured work systems. Education and training in Autism and developmental disabilities, 49, 568-575.

Parsons, S., Charman, T., Faulkner, R., Ragan, J., Wallace, S., \& Wittemeyer, K. (2013). Commentary--Bridging the research and practice gap in autism: the importance of creating research partnerships with schools. Autism, 17(3), 268-280. doi:10.1177/1362361312472068

Polkinghorne, D. E. (2007). Validity Issues in Narrative Research. Qualitative Inquiry, 13(4), 471-486. doi:10.1177/1077800406297670

Round, P. N., Subban, P. K., \& Sharma, U. (2016). 'I don't have time to be this busy.'Exploring the concerns of secondary school teachers towards inclusive education. International Journal of Inclusive Education, 20(2), 185-198.

Soto-Chodiman, R., Pooley, J. A., Cohen, L., \& Taylor, M. F. (2012). Students with ASD in mainstream primary education settings: Teachers' experiences in Western Australian classrooms. The Australasian Journal of Special Education, 36(2), 97-111. doi:10.1017/jse.2012.10

SurveyMonkey Inc. San Mateo, California, USA. Retrieved from www.surveymonkey.com Walker, H. M. (2004). Commentary: Use of evidence-based interventions in schools: Where we've been, where we are, and where we need to go. School Psychology Review, 33(3), 398-408.

Wong, C., Odom, S. L., Hume, K. A., Cox, A. W., Fettig, A., Kucharczyk, S., . . Schultz, T. R. (2015). Evidence-based practices for children, youth, and young adults with autism spectrum disorder. Chapel Hill: The University of North Carolina, Frank Porter Graham Child Development Institute, Autism Evidence-Based Practice Review Group.

Yin, R. K. (2014). Case study research: Design and methods (5th ed.). Thousand Oaks, CA: Sage publications. 
Table 1. How useful were elements of the toolkit?

\begin{tabular}{lllll}
\hline & $\mathrm{N}$ & Mean & Median & Mode \\
\hline Information about autism. & 19 & 5.26 & 6 & $4^{\mathrm{a}}$ \\
Information about structured teaching. & 19 & 5.63 & 6 & 6 \\
Information about visual schedules. & 19 & 5.63 & 6 & 7 \\
Information about work systems. & 19 & 5.68 & 6 & 6 \\
Links to other information online. & 18 & 5.56 & 6 & 6 \\
Links to videos. & 18 & 5.44 & 6 & 4 \\
Instructions on how to implement visual & 19 & 5.84 & 6 & 6 \\
schedules. & & & & \\
Instructions on how to implement work & 19 & 5.95 & 6 & $6^{\mathrm{a}}$ \\
systems. & & & & \\
Examples of visual schedules. & 19 & 5.84 & 6 & 7 \\
Examples of work systems. & 19 & 5.95 & 6 & $6^{\mathrm{a}}$ \\
Templates for implementing visual & 19 & 5.90 & 6 & $6^{\mathrm{a}}$ \\
schedules and work systems. & & & & \\
Pull-out "at a glance" information sheets. & 19 & 5.74 & 6 & 7 \\
Implementation checklist. & 19 & 5.74 & 6 & 7 \\
\hline
\end{tabular}

a. Multiple modes exist. The smallest value is shown

Table 2. Usefulness and useability of visual schedules and work systems.

\begin{tabular}{cccc}
\hline $\mathrm{n}$ & Mean & Median & Mode \\
\hline Perceived usefulness in teaching your student
\end{tabular}
all useful, 4 = somewhat useful, 7 = very useful):

$\begin{array}{lllll}\text { Visual schedules or } & 19 & 6.21 & 7 & 7\end{array}$

timetables

$\begin{array}{lllll}\text { Work systems } & 19 & 6 & 6 & 7\end{array}$

Perceived usefulness in teaching other students in the class:

$\begin{array}{lllll}\text { Visual schedules or } & 19 & 6.42 & 7 & 7\end{array}$

timetables

$\begin{array}{lllll}\text { Work systems } & 19 & 5.74 & 6 & 7\end{array}$

How easy would it be to implement $(1=$ very difficult, $4=$ neither difficult nor easy, 7 = very easy): 
Visual schedules or

timetables?

Work systems?

$5.42 \quad 5$

5

How likely would you be to use $(1=$ not at all likely, $4=$ somewhat likely, $7=$ very likely):

Visual schedules or

19

6.63

7

7

timetables?

Work systems?

19

5.74

6.

7

Table 3. Wilcoxon signed rank test of knowledge and confidence.

\begin{tabular}{|c|c|c|c|c|c|c|c|c|}
\hline & \multicolumn{3}{|c|}{ Before reading toolkit } & \multicolumn{5}{|c|}{ After reading toolkit } \\
\hline & $\mathrm{n}$ & $\overline{\text { Median }}$ & Std. Deviation & $\mathrm{n}$ & Median & Std. Deviation & $\mathrm{Z}$ & $\bar{p}$ \\
\hline $\begin{array}{l}\text { Knowledge of visual } \\
\text { schedules }\end{array}$ & 19 & 5 & .91 & 19 & 6 & 1.05 & $-1.542^{\mathrm{b}}$ & .123 \\
\hline $\begin{array}{l}\text { Knowledge of work } \\
\text { systems }\end{array}$ & 19 & 4 & 1.34 & 19 & 5 & 1.45 & $-.892^{\mathrm{b}}$ & .372 \\
\hline $\begin{array}{l}\text { Confidence using } \\
\text { visual schedules }\end{array}$ & 19 & 5 & .99 & 18 & 6 & 1 & $-2.543^{\mathrm{b}}$ & $.011^{*}$ \\
\hline $\begin{array}{l}\text { Confidence using } \\
\text { work systems }\end{array}$ & 19 & 4 & 1.49 & 19 & 6 & 1.12 & $-2.708^{b}$ & $.007 *$ \\
\hline
\end{tabular}

Wilcoxon Signed Ranks Test

Based on negative ranks.

$*$ Represents significant difference $(\mathrm{p}<.05)$ 